\title{
ENFERMEDAD Y DESPLAZAMIENTO, UNA LECTURA POSTCOlONiAL de LA EDAD DE HIERRO DE J.M. COETZEE Y Mi hERMANO DE JAMAICA KinCAID*
}

\section{Daniela Buksdorf K.**}

\section{Resumen}

El presente artículo plantea un análisis comparativo de las novelas La edad de hierro (1990) del escritor sudafricano J.M Coetzee y Mi hermano (1997) de la escritora caribeña Jamaica Kincaid, atendiendo al contexto postcolonial de los países en los que transcurren las historias: Sudáfrica y Antigua, respectivamente. La siguiente lectura sugiere que la enfermedad funciona como un agente catalizador en la vida de las protagonistas de ambas novelas, haciendo que ellas no sólo adquieran un mayor conocimiento de la realidad, sino que además reaccionen frente a esta.

Palabras clave: Postcolonialismo, enfermedad, desplazamiento, Coetzee, Kincaid.

\section{DISEASE AND DISPLACEMENT, A POSTCOLONIAL READING J.M. CoETZEE'S AgE OF IRON AND JAMAICA KinCAID's $M Y$ BROTHER}

\begin{abstract}
This article presents a comparative analysis of the novels Age of iron (1990), written by the South African writer J.M Coetzee and My brother (1997) by the Caribbean writer Jamaica Kincaid, considering the postcolonial context of the countries where the stories unfold: South Africa and Antigua respectively. The following reading suggests that disease acts as a catalyst in the lives of the protagonists of both novels, making them not only gain a greater understanding of reality, but also to react against this.
\end{abstract}

Keywords: Postcolonialism, disease, displacement, Coetzee, Kincaid.

Recibido: 15-12-2014

Aceptado: 09-01-2015

* Enfermedad y desplazamiento, una lectura postcolonial de La edad de hierro de J.M. Coetzee y Mi hermano de Jamaica Kincaid es parte de la investigación realizada por la autora para acceder al grado de Magíster en la Universidad Adolfo Ibáñez. Investigación defendida y aprobada el 23 de enero de 2014.

** Chilena. Magíster Literatura Comparada Universidad Adolfo Ibáñez. Magíster (C) Literatura Hispanoamericana Pontificia Universidad Católica, Santiago, Chile. dbuksdorf@uc.cl 
Este artículo presenta dos novelas contemporáneas, La edad de hierro (1990), de J.M. Coetzee, y Mi hermano (1997), de Jamaica Kincaid, que hacen visibles las problemáticas sociales y políticas que emergen de antiguas colonias inglesas, que son precisamente el espacio en que transcurren las historias y el lugar de origen de los autores (Sudáfrica y Antigua respectivamente). Asimismo, estos textos hacen una denuncia de la difícil y hasta precaria situación que han atravesado estos países, exponiendo las profundas marcas que deja el colonialismo. Las novelas tienen en común, además, la enfermedad como hilo conductor de las historias que desarrollan; en el caso de la novela de Coetzee, el cáncer terminal que sufre la protagonista, y en la novela de Kincaid, es el hermano de la protagonista quien está enfermo de sida.

La enfermedad opera como un eje articulador del sentido, pues modifica el actuar y la forma de pensar de ambas protagonistas, quienes al experimentarla -una como enferma y la otra como testigo- son capaces de desmontar las relaciones binarias insertas en sus vidas, que han sido construidas por el discurso hegemónico. En ambos casos, la enfermedad no sólo les permite acceder a cierto conocimiento del que estaban privadas sino también alejarse de los discursos dominantes mediante una suerte de desplazamiento que les entrega una visión más amplia de la realidad.

\section{La edad de hierro y Mi hermano como novelas poscoloniales}

La práctica deconstructiva del postcolonialismo, desde una perspectiva crítica, permite revisar los discursos dominantes y observar cómo éstos operan en las ex colonias. Según Walter Mignolo, el concepto no se agota con la mera referencia a ese momento posterior al colonialismo, sino que es ante todo un cuestionamiento crítico de sus legados: "No entiendo por "postcolonial" un momento en el cual se han superado los colonialismos, sino desde una posición crítica frente a sus legados. En este sentido, entiendo por "postcolonial"... un momento de crítica a los legados de la modernidad" (Mignolo 29). Por su parte, Sandro Mezzadra, complementa la idea de Mignolo respecto al sentido crítico, identifica el tiempo postcolonial como aquel en el que la experiencia colonial parece estar consignada al pasado y al presente, e implica una carga de dominación, pero también de insubordinación, lo que permite analizar 
desde la crítica imperialista la producción discursiva que se encuentra inserta incluso en el presente de las ex colonias (Mezzadra 264).

En Mi hermano, Kincaid deja claras las diferencias entre Antigua y Estados Unidos, al comparar la realidad de la isla con la de Norteamérica, mostrando las abismantes diferencias entre el país del Primer Mundo y la isla caribeña tercermundista. Algo similar se deja entrever en la novela de Coetzee, cuando la protagonista señala que su hija ha dejado Sudáfrica optando por la seguridad que le entrega Estados Unidos.

Gayatri Spivak observa en el Tercer Mundo (división geopolítica a la que corresponden Antigua y Sudáfrica) un cambio en la relación de las antiguas colonias con la hegemonía, donde el colonialismo propiamente dicho se transforma en neocolonialismo, aquella empresa del imperialismo en la que predomina la dependencia económica en lugar del carácter territorial (15). ${ }^{1}$ Aclara la diferencia entre los distintos términos, situando al postcolonialismo como la evolución del colonialismo al neocolonialismo ${ }^{2}$. Siguiendo a Spivak, se puede ver entonces una nueva relación de dependencia entre las ex colonias ubicadas en el Tercer Mundo y la hegemonía representada por los países del Primer Mundo. La relación de dependencia tanto económica como cultural se observa en la zona de contacto que se establece entre las ex colonias y, en el caso de ambas novelas, Estados Unidos. Mary Louise Pratt propone que la zona de contacto son aquellos lugares en los que confluyen o entran en comunicación culturas que han seguido históricamente trayectorias separadas y que establecen una sociedad, con frecuencia, en el contexto de una relación de colonialismo (26), o en el caso de estas novelas, de dependencia. En La edad de hierro, la hija de la señora Curren (la protagonista) decide dejar Sudáfrica para vivir en Estados Unidos, un país seguro, sin violencia ni corrupción, mientras que, en Mi hermano, Kincaid deja Antigua para radicarse en Estados Unidos que es el lugar donde puede conseguir las medicinas para el tratamiento de su hermano enfermo. Las novelas muestran que la zona

1 En este contexto, para Spivak, no es relevante la diferencia entre colonialismo e imperialismo.

2 Spivak define colonialismo como la formación europea que se extiende desde mediados del siglo XVIII hasta mediados del siglo XX, neocolonialismo como maniobras económicas, políticas y culturalistas dominantes y poscolonialidad como la condición global contemporánea... un tránsito de la situación que describe el primer término a la situación que describe el segundo (174). 
de contacto entre distintas culturas se presenta en una relación en la que Estados Unidos aparece como la cultura dominante que, por un lado, juzga y rechaza el apartheid en Sudáfrica (en el caso de La edad de hierro) $y$, por otro, provee los recursos para el tratamiento de un enfermo que reside en Antigua (en el texto de Kincaid).

Tal como indica Pratt, en estas zonas de contacto las relaciones de poder son asimétricas (27). La dominancia de Estados Unidos se presenta de distintas maneras en las novelas. En el caso de Mi hermano, esta es más evidente, ya que está representada por la misma Kincaid, quien, además de proporcionar los recursos y medicinas para el tratamiento de Devon, continuamente muestra la superioridad de Estados Unidos en las comparaciones que hace entre Antigua y este país. Como ya se mencionó antes, esta relación en $\mathrm{La}$ edad de hierro, aunque menos evidente, es igualmente fundamental para la novela: la señora Curren le escribe a su hija -radicada en Estados Unidos- y le relata los hechos que le han ido revelando la verdadera situación que vive Sudáfrica. De esa manera, la carta se convierte, sin quererlo la señora Curren, en una corroboración de los argumentos que su hija esgrime para abandonar su país.

Como se puede ver, en ambas novelas existe un diálogo con Estados Unidos, una suerte de comparación en la que, evidentemente, este país se ubicaría en una posición superior, al igual que quienes lo habitan: la hija de la señora Curren y Jamaica Kincaid, la hermana que abastece de medicamentos y recursos a Devon.

La edad de hierro narra la historia de la señora Curren, una profesora jubilada que, aunque ha sido diagnosticada con un cáncer óseo en etapa terminal, decide no tratarse y contarle a su hija por medio de una carta (una vez que haya muerto) acerca de sus últimos días. La protagonista encuentra en el patio de su casa a Vercueil, un vagabundo que progresivamente se va acercando a ella, al principio haciendo trabajos domésticos para terminar cuidándola y acompañándola en su enfermedad. Este hombre se convierte en el depositario de la confianza de la señora Curren, quien le pide que una vez que ella muera, sea él quien envíe la carta a su hija en Estados Unidos.

La novela está ambientada en la época final y más dura de la segregación racial, que data desde mediados del siglo XX. La señora Curren es una mujer blanca de situación acomodada que vive en Cape 
Town. Pareciera que esta mujer recién es consciente de la violencia y los problemas sociales por los que atraviesa su país cuando decide no tratar su enfermedad. Junto a la señora Curren vive Florence, la criada, cuyo hijo mayor, Bheki, es un joven de quince años que lucha por la revolución y la caída del apartheid.

El desplazamiento vivido por la protagonista se debe al real conocimiento que adquiere sobre la situación de su país cuando lo experimenta en primera persona, y conoce desde cerca los efectos del apartheid en la población segregada. Al ver cómo los policías atacan a los niños, la violencia en Cape Flats y cómo invaden su casa la señora Curren se moviliza por distintas situaciones que le permiten tener una visión más amplia de la realidad para poder desplazarse entre los márgenes de la relación binaria del opresor y el oprimido: "Accordingly, Age of Iron is understood to be a novel treating the effects of apartheid on the psyches of both the oppressor and the oppressed. Such an understanding fails to register the ways in which the protagonists of Coetzee's novel rarely belong to this sort of easy binary division" (Barnett 294).

En Mi hermano, Jamaica Kincaid narra en primera persona ${ }^{3}$ la enfermedad de su hermano Devon, quien muere de sida en Antigua, país natal de la autora. Kincaid, quien vive en Estados Unidos desde los dieciséis años, recibe una llamada en su casa en Vermont, en la que le informan que su hermano tiene sida. Viaja a Antigua y se encuentra con su hermano, al que dejó de ver cuando éste tenía sólo tres años, convertido ahora en adulto. Devon está moribundo en una cama de hospital, aislado en una sucia sala y sin acceso a un tratamiento médico. En Kincaid afloran los recuerdos de infancia, sobre todo aquellos que aluden a la relación con su madre, la que retoma a propósito de la enfermedad de Devon, y frente a la cual adopta una posición paternalista, ya que es quien le facilita los medicamentos y tratamientos, marcando una superioridad en comparación con su familia: ella tiene una vida ejemplar en Estados Unidos, junto a su marido y sus hijas, lugar desde el que puede tener una postura crítica sobre Antigua; sin embargo, ella circula sin tener una

3 Mi hermano es una novela de autoficción, género que no pretende dar un testimonio verídico sino que manipula los recuerdos del autor(a) con fines estéticos, siendo una ficcionalización de sus experiencias. Se sugiere leer, para una mayor profundización del género, a Serge Doubrovsky, Fils, París, Galilée, 1977. 
postura fija, lo que se observa en la relación ambivalente que tiene con su familia movilizándose entre al amor y el odio, como también entre el enojo y el cansancio, llegando a cuestionarse el por qué se ha visto involucrada en esa situación, y prácticamente deseando que Devon muera para volver a su vida regular.

La edad de hierro es publicada en 1990, año en que finaliza la política de segregación racial con la libertad política de los habitantes de color. Coetzee escribe esta novela en su natal Sudáfrica. A través de la señora Curren, y de la representación que hace la protagonista de lo vivido durante sus últimos días de vida, narra esa realidad que ella nunca antes había presenciado frente sus ojos, y que los medios de comunicación prefieren no informar: "La radio no dice nada de los disturbios en las escuelas, la televisión no dice nada y los periódicos no dicen nada" (Coetzee 47). La protagonista se entera de lo que ocurre gracias a Florence, sin embargo, en un primer momento se resiste a aceptar la situación e insiste en compararla con el tiempo pasado, en el que ella era una niña y los ingleses tenían el control del país como una época mejor.

Mi hermano comienza cuando Jamaica Kincaid recibe una llamada telefónica en su casa en Vermont: "yo estaba en mi casa, en Vermont, enfrascada en el bienestar de mis hijos, enfrascada en el bienestar de mi marido, enfrascada en mi propio bienestar" (Kincaid 8). Ese llamado rompe la paz perfecta de su hogar, la interrumpe y la hace viajar a Antigua, su país natal, haciéndose cargo económicamente del tratamiento para su hermano. En su artículo "On Seeing England for the First Time", Kincaid señala la fuerte presencia inglesa en la isla mientras ésta todavía es colonia y cuenta su manera de vivir, como si estuviera en Inglaterra, rodeada de productos y costumbres de origen inglés: "But this breakfast was Made in England like almost everything else that surraounded us, the exceptions being the sea, the sky, and the air we breathed" (33). Luego, en Mi hermano, muestra cómo todo lo que fue "hecho en Inglaterra" se ha deteriorado después del retiro del imperio. Kincaid deja en evidencia cómo el paso del tiempo y el fin de la colonia han sido variables importantes en el descuido del país: "Antigua es ese tipo de sitio: las piezas y componentes de prácticamente todo ya no se fabrican en ningún lugar del mundo; nada en Antigua es de fabricación propia" (22). Esta dependencia que describe Kincaid se hace visible también en la 
dependencia que tiene Devon del medicamento, el AZT, que no se puede conseguir en Antigua y que ella debe conseguir en Estados Unidos:

Las lecturas postcoloniales de Mi hermano interpretan el SIDA de Devon y la situación de dependencia en que lo pone con respecto a su hermana -porque sólo ella puede comprar y enviar desde Estados Unidos las medicinas que mejoran su calidad de vida y dilatan la muerte- como una alegoría del sometimiento primero colonial de Antigua y posteriormente postcolonial. (Stecher 192)

Kincaid se ha distanciado de Antigua, ha dejado el calor caribeño y lo ha cambiado por el frío de Vermont, lo que le permite tener un parámetro de comparación, criticando la precariedad de su país natal, en un duro contraste con Estados Unidos: "Hay gente que se queja de que los hospitales de Estados Unidos cargan seis dólares por una dosis de Tylenol; se sorprenderían al ver esta otra forma de llevar un hospital: tráigase sus propias medicinas" (30).

Mientras la protagonista de La edad de hierro compara la situación actual sudafricana con "su época" (la tranquilidad del apartheid, considerando la perspectiva de una mujer blanca), Kincaid contrasta la precariedad de Antigua con la superioridad de Estados Unidos. Así, ambas novelas, aunque de distinta manera, tienen un vínculo con Norteamérica: la señora Curren le escribe a su hija que abandonó Sudáfrica para radicarse en Estados Unidos, mientras que la esperanza de vida de Devon también se encuentra en ese país desde donde su hermana le envía las dosis de AZT que mejoran sus condiciones de enfermo de VIH.

Como se puede ver, Estados Unidos se presenta en ambas novelas como un mejor lugar para vivir, en el que las normas funcionan y hay seguridad, es el espacio que ofrece bienestar a Kincaid y tranquilidad a la hija de la señora Curren: "En la foto que me enviaste de los dos chicos en canoa ... si por algún infortunio alguna vez se caen de la canoa, se quedarán flotando a salvo, sostenidos por sus flotadores de color naranja, hasta que una motora vaya a buscarlos y los deje en tierra y todo vuelva a estar bien (219).

La tranquilidad y seguridad que describe la señora Curren no existe en Sudáfrica, los niños como Bheki no tienen acceso a lagunas y canoas, 
la situación no lo permite, sus escuelas son consumidas por el fuego, mientras en Estados Unidos los nietos de la señora Curren gozan de tranquilidad en un entorno seguro donde pareciera que nunca correrán peligro alguno. En el caso de Kincaid, su hogar en Estados Unidos es sinónimo de tranquilidad y felicidad: "Estaba muy contenta de haber llegado a mi hogar, es decir, al hogar que había formado por mí misma, el hogar de mi vida adulta" (Kincaid 82).

\section{La enfermedad en Mi hermano y La edad de hierro}

Estas novelas comparten como tema central la enfermedad y es esta la que le permite a las protagonistas acceder a un conocimiento que antes de atravesar por dicha experiencia no era importante para el desarrollo de sus vidas. La enfermedad gatilla en las mujeres de ambas novelas una cercanía con ciertos aspectos de sus vidas que desconocen o han renegado (como el apartheid para la señora Curren o la historia familiar para Kincaid).

Se puede entender la enfermedad como parte natural del proceso de la vida, como la etapa final previa a la muerte. Michel Foucault (1961) señala que "La enfermedad no es una esencia contra natura, es la naturaleza misma, pero en un proceso inverso" (32), entendiendo así el nacimiento como el inicio y la muerte como el fin, ambas instancias esenciales para la vida. No sería "natural" por ejemplo, la muerte por un accidente, esto es, la vida interrumpida y acabada violentamente, y no a través de un proceso del cuerpo mismo, como indica Norbert Elias (1987) en La soledad de los moribundos: "La muerte producida por enfermedad subraya el carácter natural del proceso, el 'caso normal'" (61).

El carácter de "proceso" que se le atribuye a la enfermedad está presente en ambas novelas: la señora Curren empeora a medida que transcurre la narración, mientras que Devon experimenta mejorías y reveces dada la poca disciplina con la que mantiene su tratamiento. Finalmente, ambos protagonistas fallecen, completando así el proceso de la vida. Es precisamente el proceso con el que se vive la enfermedad el que demuestra, en ambas novelas, la naturaleza del desplazamiento de las protagonistas. En el caso de la señora Curren, el desplazamiento se podría decir que es constante y divergente, mientras más empeora su estado de salud, más distante está de su posición inicial. En el caso de Mi hermano, el desplazamiento es experimentado por Kincaid, dada 
la enfermedad de su hermano, cuyo proceso es inconstante en cuanto a las indicaciones médicas, abandonando y retomando este tratamiento, lo que coincide con el desplazamiento inestable de Kincaid, quien pasa del amor al odio y viceversa hacia su hermano Devon, de manera reiterada.

La enfermedad puede entenderse como una situación de "no normalidad" a través del opuesto binario sano/enfermo. Susan Sontag (1966) en su ensayo La enfermedad y sus metáforas, explica el carácter de otredad que conlleva la enfermedad: "La enfermedad es el lado nocturno de la vida, una ciudadanía más cara. A todos, al nacer, nos otorgan una doble ciudadanía, la del reino de los sanos y la del reino de los enfermos... tarde o temprano cada uno de nosotros se ve obligado a identificarse, al menos por un tiempo, como ciudadano de aquel otro lugar" (11). Se podría ubicar entonces a la enfermedad, al enfermo, en el lugar del otro, siendo este sujeto vulnerable frente al individuo sano. En este artículo, se entiende la enfermedad como un proceso de alienación de los personajes, que les permite desplazarse dentro del sistema en el que están insertos. Tanto la señora Curren como Jamaica Kincaid experimentan esta alineación, la primera como enferma que siente los estragos de la enfermedad no solo en su cuerpo, sino también en la relación con su entorno, mientras que Kincaid experimenta el dolor y las consecuencias de la enfermedad de su hermano, desplazándose hacia la posición de Devon.

En ambas novelas la enfermedad es representada por la metáfora de la invasión, de lo ajeno que rompe las fronteras del cuerpo para atacar, operando tanto para el cáncer como el sida: "Ahora es el cáncer la enfermedad que entra sin llamar, la enfermedad vivida como invasión despiadada y secreta" (Sontag, 13). Una lógica similar funciona con el sida: "En la descripción del sida el enemigo es aquello que causa la enfermedad, un agente infeccioso proveniente del exterior... Las células del cuerpo invadido se transforman en invasoras" (104-105). Entendiendo la metáfora de la enfermedad como el resultado de la invasión de un externo, se podría entender la condición colonial en la que vivieron los países en los que se desarrollan las novelas como sociedades enfermas. En este caso, se puede asociar a Inglaterra con el invasor, con la figura del extranjero que traspasa los límites de estos cuerpos representados por los países colonizados, para invadirlos e instalarse en ellos, prolongando así la condición de enfermos no sólo a personas sino también a sociedades 
y países. Es en parte esta sociedad enferma, víctima del colonialismo, y su posterior abandono hacia donde se dirigen las críticas sociales presentadas por Coetzee y Kincaid.

En el caso del cáncer, en particular, son variadas las metáforas que rodean a la enfermedad. En contraposición a la analogía presentada anteriormente, otra imagen que ronda a esta enfermedad es aquella de origen interno, y que indica que la causa de esta se debe a la producción de un cuerpo extraño que, desde dentro, desde el mismo cuerpo, le hace daño y lo enferma, Susan Sontag lo identifica como "el bárbaro dentro del cuerpo" (64). En La edad de hierro, la señora Curren explica su enfermedad, la personifica en este "algo" que la destruye desde dentro: "El destino envía a cada uno la enfermedad que se merece. La mía es una enfermedad que me devora desde dentro. Si me abrieran me encontrarían hueca como una muñeca, una muñeca con un cangrejo sentado dentro relamiéndose, deslumbrado por la llegada de la luz ... Me roe los huesos ahora que no queda carne" (Coetzee 129). Ella atribuye su enfermedad a la vergüenza: "La acumulación de toda la vergüenza que he sufrido en mi vida me ha provocado cáncer. Así es como empieza el cáncer: el cuerpo se vuelve maligno de tanto sentir asco de sí mismo y empieza a roerse a sí mismo" (164). Ese sentimiento se debe a lo que ella representa, esto es, la raza blanca que oprime y discrimina a las personas de raza negra.

Por su parte, el sida es una enfermedad estigmatizada, también rodeada de metáforas, que se manifiesta a través de distintos síntomas y dolencias, creando una dependencia con los medicamentos que le ayudan a palear los efectos de estos. Esa dependencia ha sido analizada por el escritor argentino Daniel Link (2001) en su artículo "Enfermedad y cultura: política del monstruo": "La enfermedad conecta indefinidamente, y de manera masiva, al ser humano con la maquinaria médico-farmacológica... a diferencia de las radioterapias y quimioterapias propias del siglo XX, no es tanto un envenenamiento como una suspensión indefinida del combate. El SIDA es, efectivamente, la Enfermedad del capitalismo tardío" (253-4). Esta relación de dependencia con la industria farmacológica es incluso más precaria en países como Antigua, donde no hay acceso a los medicamentos, lo que obliga, en el caso de Devon, a mantener una relación de dependencia con Estados Unidos a través de su hermana. Esta dependencia es el núcleo de la relación entre 
Kincaid y su hermano; en otras palabras es la enfermedad y el acceso al medicamento lo que vincula a los hermanos. Es así como al comienzo de la novela es Kincaid quien ejerce la posición dominante, es la proveedora representante del Primer Mundo, mientras que Devon, representante del Tercer Mundo, se ubica en la posición dominada. Esa posición le permite a Kincaid tener una postura crítica y de superioridad frente a su familia y su país de origen. Esta relación de dependencia ejemplifica la situación neocolonial según lo entiende Mary Louise Pratt (2010):

La esencia del neocolonialismo consiste en que el Estado a él sometido es, en teoría, independiente y posee todos los atributos exteriores de la soberanía internacional. En realidad, su sistema económico y, por ende, su rumbo político, están dirigidos desde afuera, por lo general a través de medios económicos y monetarios, como el control sobre el comercio y la actividad financiera. La condición neocolonial implica vivir en un aprieto. (411)

Así, mientras la madre se preocupa de alimentar y asear a Devon, Kincaid busca los tratamientos, contratando los servicios del doctor Ramsey y comprando el AZT. Tal como indica Georg Simmel (2010) en su libro Cultura líquida y dinero, la relación que se establece existiendo un pago de por medio es mucho menos íntima: "Con el pago monetario ya nadie se ofrece a sí mismo, sólo se ofrece algo sin ningún lazo con el individuo" (7). Se podría inferir que Kincaid prefiere hacerse cargo del aspecto económico, tal vez, para demostrar su superioridad y generar cierta distancia en cuanto a la situación y así evitar la intimidad que conllevan los cuidados físicos que le entrega su madre a Devon. A su vez, la relación de la señora Curren con Vercueil en un comienzo también se sustenta en un acuerdo económico, pues le paga al hombre, para que realice trabajos domésticos: le ayuda a hacer andar su auto y, lo más importante, una vez que ella muera debe enviarle la carta a su hija. De hecho, la señora Curren pacta con Vercueil esta relación: “Si quiere que le pague, tendrá que ganárselo -le he dicho-. No le voy a dar dinero por nada" (Coetzee 28).

El hecho de que ambas mujeres tengan recursos económicos y sean, gracias a esto, las partes dominantes en las relaciones que establecen, ya podría demostrar cierto quiebre en la lógica de los opuestos binarios en la que suele ser el hombre el ente dominante y proveedor, aquí son 
los hombres (Vercueil y Devon) los que dependen económicamente de estas mujeres. Sin embargo, en el desarrollo de las novelas se puede ver cómo cambian estas relaciones: la señora Curren, dada su condición de enferma, necesita cada vez más a Vercueil, generándose entre ellos una mayor cercanía; y en el caso de Kincaid con su hermano, la relación deja de ser sólo de dependencia económica pues ella se involucra a medida que acompaña más a Devon durante la enfermedad.

\section{El desplazamiento}

Tanto en Mi hermano como en La edad de hierro, las protagonistas experimentan un desplazamiento que en ambos casos está ligado a la experiencia de la enfermedad, la que, según se señaló, es ese otro lugar en el que no se quiere permanecer. Para poder identificar el desplazamiento que experimentan las protagonistas, es importante identificar el lugar (tanto físico, social como emocional) en el que se encuentran inicialmente estas mujeres, y el proceso que experimentan y que las moviliza.

Los vínculos que mantienen las protagonista -la señora Curren con Florence y Vercueil, y Kincaid con su hermano- se pueden entender como relaciones binarias, un sistema jerarquizado de oposiciones en los que, en ambos casos, las protagonistas se ubican en la posición dominante. Estas relaciones de poder se pueden deconstruir, es decir, destruir, desmontar y desarmar, para construir, montar y volver a armar: "no se trata de cambiar o invertir los términos de una jerarquía dada, sino de transformar la estructura misma de la jerarquía" (De Peretti 129). Se puede así entender entonces que los desplazamientos experimentados por las protagonistas no implican que sus posiciones se inviertan, sino que operan desde un sistema en el que no existe dominancia entre ellos.

En la novela de Coetzee, la protagonista se encuentra inicialmente en una posición etnocéntrica, lo que se puede ver reflejado en juicios morales y comparaciones con los tiempos cuando imperaban las costumbres coloniales. El etnocentrismo se puede entender, en palabras de Tzvetan Todorov como "el hecho de elevar, indebidamente, a la categoría de universales los valores de la sociedad a la que yo pertenezco" (21). Esa actitud de la protagonista se presenta reiteradamente, sobre todo al comienzo de la novela, al no entender los conflictos sociales que implica el apartheid. La señora Curren desconoce la situación por la que atraviesan los sectores segregados y es a través de Florence que comienza 
a enterarse de lo que ocurre a su alrededor: "Mis conocimientos sobre lo que está pasando en Guguletu se basan exclusivamente en lo que Florence me cuenta" (Coetzee 47). Es la criada la que acerca el apartheid a la protagonista y hace posible que sea capaz de movilizarse, dejando de lado los juicios y comparaciones.

El acceso a la información por medio de Florence y sus hijos, como también el hecho de vivir en primera persona la violenta experiencia del apartheid permite a la señora Curren avanzar es su desplazamiento, al acompañar a Florence a Guguletu (suburbio donde vive parte de la población de color) buscando a Bheki. Al llegar allá, la señora Curren ya puede notar un ambiente hostil: "Ahora olía a quemado, a cenizas mojadas, a goma quemada. Lentamente hemos avanzado por una calle ancha sin asfaltar con casas como cajas de cerillas. Por nuestro lado ha pasado patrullando una camioneta protegida con una malla de alambre" (104). Finalmente, entra a un edificio abandonado y se encuentra con cinco cuerpos de jóvenes sin vida, entre los cuales estaba el hijo de Florence.

La muerte de Bheki es para la señora Curren, el hito que marca su desplazamiento. Después de presenciar aquella escena, con los jóvenes muertos y las casas en llamas, modifica su conducta y su opinión, lo que se ve reflejado en lo que le escribe a su hija en relación a esos hechos: "No te cuento esta historia para que sientas lástima de mí, sino para que sepas cómo son las cosas" (119). La señora Curren se convierte entonces en la voz de esta verdad que ocurre en silencio, de la que no informa la policía ni los periódicos, una verdad que su hija sólo puede conocer a través de la voz de su madre.

Así como la señora Curren experimenta un desplazamiento a nivel social, también lo experimenta a nivel espiritual, lo que se ve reflejado en su relación con Vercueil. Su primera impresión al encontrar al vagabundo en el patio de su casa coincide con el día en que recibe la noticia sobre su estado de salud: "Dos cosas, en el lapso de una hora: la noticia, largo tiempo temida, y ese otro reconocimiento, esa otra anunciación. La primera de las aves carroñeras, rápida, certera" (12). Pareciera que Vercueil personaliza su castigo, la llegada de la muerte inminente. Ella lo identifica con un ave de rapiña, pero en lugar de ahuyentarlo lo invita a entrar a su casa: le da techo y comida, lo hace parte de su vida, de la misma manera en que acepta su estado de salud, sabiendo que pronto va a morir. De esta manera, el vagabundo comienza a formar parte de la 
vida de la señora Curren, siendo parte de su cotidianeidad. Pero al poco tiempo, ella le encarga un trabajo que sólo él puede hacer, equilibrando de esa manera la relación de dependencia: "-Si me muero, me gustaría que hiciera algo por mí. Hay algunos papeles que quiero enviar a mi hija... Son documentos privados, cartas privadas. Son la herencia de mi hija. Son lo único que puedo darle, lo único que va a aceptar, procedente de este país" (40). Al elegir a Vercueil para que haga la entrega de la carta, la protagonista depende de la voluntad del vagabundo, quien al finalizar la conversación le confirma que realizará el encargo. Como se dijo antes, la carta escrita por la señora Curren a su hija es su testimonio de vida, y puede entenderse como la entrega de su propia vida a Vercueil. Desde el momento en que el vagabundo es el encargado de la carta que escribe la señora Curren, ésta ha comenzado su desplazamiento, por lo que el hombre que vio por primera vez como un ave carroñera, es ahora el depositario de su confianza. Junto a este movimiento, la protagonista progresivamente se acerca también a la muerte.

En un comienzo la relación entre mujer y vagabundo es desigual; mientras la señora Curren demuestra interés por el vagabundo, este no retribuye de manera inmediata el interés manifestado por la anciana, sino hasta el momento en que la mujer considera la idea de quitarse la vida, y le pide ayuda al vagabundo, quien manifiesta interés en ella por primera vez. El interés manifestado por él se podría entender siguiendo la idea que el vagabundo simboliza la muerte: la señora Curren busca la muerte a través del suicidio en lugar de esperarla como resultado de su enfermedad, generando así un mayor interés por parte de Vercueil. La idea de la protagonista, de terminar con su vida, se puede deber al impacto que le produce ver el cuerpo de Bheki sin vida y, con ello, pagar y redimirse por haber actuado como testigo y cómplice silencioso de lo que en su país ocurría: "Quiero venderme, redimirme, pero no consigo decidir cómo hacerlo" (134). La señora Curren se confiesa con Vercueil, se desahoga y le transmite sus pensamientos, y finalmente, regresan juntos a casa. No queda claro si la mujer no se atreve a lanzarse precipicio abajo o cambia de opinión.

A los pocos días, la casa de la señora Curren es allanada por la policía, dada esta invasión, la mujer se aleja y no quiere volver a su hogar, por lo que decide caminar por la calle, lugar en el que la encuentra tendida en el suelo Vercueil, quien la carga en sus brazos para llevarla de regreso a 
casa, trayecto que le demora toda la noche. La experiencia vivida por la señora Curren, de pasar la noche en la calle, la instala en el mismo lugar en el que se encontraba Vercueil el día que ella lo encuentra en el patio de su casa. Ella es rescatada por el vagabundo; el ave de rapiña se ha convertido en un ángel "¿Cuándo llegaría el momento en que se le cayera la chaqueta y le brotaran unas alas enormes de los hombros?" (182).

Desde el regreso a casa la relación entre ambos cambia drásticamente, ahora Vercueil demuestra una preocupación real por ella: “Todos los días va a hacer la compra. Por las noches cocina, luego se inclina sobre mí, vigilándome para que coma" (213). Pareciera que la mujer y el vagabundo ya tienen una rutina, comparten la vida, así como comparten la cama: ella siente frío y le pide que duerman juntos, compartiendo así incluso el espacio más íntimo del hogar. El cambio en la conducta del vagabundo es significativo, pasa de ser un hombre esquivo e indiferente a convertirse en el compañero y apoyo de la señora Curren. El desplazamiento lo experimentan ambos personajes, ya que si en un comienzo los separaban diferencias abismantes, éstas ya no existen, así, finalmente la señora Curren muere en brazos de Vercueil: "He vuelto a la cama, al túnel que se abre entre las sábanas frías. Las cortinas se han abierto. Él se ha metido a mi lado... Me ha cogido y me ha abrazado con una fuerza tremenda, de forma que todo el aire me ha abandonado en un momento. Un abrazo del que no se podía extraer calidez" (223).

El desplazamiento que experimenta la señora Curren es gradual y guarda íntima relación con los hechos por ella vividos. La enfermedad y el hecho de saber que morirá pronto vuelven más sensible y receptiva a la mujer, quien empieza a entender por qué su hija dejó el país que el apartheid está destruyendo. La protagonista deja el lugar en el que se encuentra inicialmente -el lugar de una mujer blanca, profesora retirada que vive una vida tranquila y segura- movilizándose por distintas realidades, como la violencia en los distritos segregados, la corrupción de la policía o la miseria de pasar una noche en la calle para llegar al lugar de los otros, de los marginados y los vagabundos.

En el caso de Mi hermano, Jamaica Kincaid experimenta la enfermedad desde fuera, pues es su hermano Devon quien ha contraído el sida. Si bien Kincaid no siente en sí misma los estragos de la enfermedad (a diferencia de la señora Curren), es esta la que le permite experimentar un desplazamiento desde el lugar emocional y familiar en el que se 
encuentra. Al enterarse de la enfermedad de su hermano, ella señala no haberse sorprendido de la situación, dado el tipo de vida que llevaba Devon: "Pero él llevaba una vida que es, al parecer, el arquetipo de las personas que contraen el virus del sida..." (Kincaid 8). Esta actitud, de juzgar a su hermano antes que nada, puede demostrar la distancia emocional que mantiene Kincaid con su familia. La distancia temporal y geográfica no le han afectado, ya que al reencontrarse con su familia y su tierra natal, sus conductas más recurrentes serán criticar a su país e intentar mantener la distancia con su familia, de la que se ha alejado desde que vive en Estados Unidos. Kincaid se siente vulnerable frente a las necesidades de su familia y por esto mismo se aleja de ellos, sin embargo, en este caso se acerca y viaja a Antigua para acompañar a su hermano y darse cuenta de lo que siente por él: “Me sorprendió descubrir que le quería; me daba cuenta de que eso era lo que sentía, amor por él, y me sorprendió porque en realidad no le conocía en absoluto" (19). Llama la atención la sorpresa de Kincaid al descubrir que siente amor por su hermano, la situación de Devon, agonizando en el hospital, afecta a Kincaid, y si al comienzo para ella la razón de la enfermedad de su hermano es su licencioso estilo de vida, ahora su agonía se debe a la precariedad de su tratamiento: "La razón por la que mi hermano estaba muriendo de sida cuando yo le vi era que, en Antigua, si se te diagnostica como portador del virus del VIH, se te considera desahuciado" (27). Se podría decir que Kincaid extrapola sus juicios, dirigidos en un principio a Devon, para referirse luego a su país natal.

La crítica que realiza Kincaid sobre Antigua trasciende la precariedad médica que, según ella, tiene a su hermano agonizando y la extiende a distintos ámbitos que van desde lo familiar hasta ciertas costumbres sociales de los antiguanos, como se observa en su encuentro con el doctor Ramsey: "Estuvo de acuerdo en encontrarse conmigo y llegó puntualmente a la cita. Menciono ese detalle porque en Antigua nadie llega nunca a la hora convenida, nadie hace nunca lo que dice que hará" (28).

Al ser Kincaid quien provee el AZT para el tratamiento de Devon, se instala como la "heroína" o la "salvación" de su hermano, manteniéndose en una postura dominante o superior, lo que le permite continuar con su postura crítica frente a su familia y su país natal. La protagonista traza un límite entre ella y su hermano, su función es suministrar el tratamiento y 
gastos médicos, ser una proveedora pero sin involucrar su vida personal. Sin embargo, este rol de proveedora no excluye sus sentimientos hacia Devon, los que son ambivalentes, un día le quiere, pero al otro no: "No le quería. Puede que lo que sentía por él fuera amor; sin embargo, ni aun ahora yo lo llamaría así" (49-50). Se podría pensar que esa irregularidad de los sentimientos se explica por el hecho de no querer pertenecer a un lugar determinado, prefiriendo circular por distintas emociones y situaciones. Después que Devon es dado de alta del hospital, y vuelve a vivir con su madre, Kincaid decide llevar a sus hijos en su próximo viaje a Antigua. Se puede ver entonces, cómo ella moviliza parte de su "vida ordenada", al involucrar a sus hijos en esta relación. Al mezclar sus dos mundos, Kincaid se desplaza; en esta relación familiar marcada por un ir y venir, une a sus hijos con su familia de origen. Kincaid se moviliza por distintos sentimientos, amor que luego no es amor, nostalgia, rencor, rabia y tristeza, conformando así un estado ambiguo e inestable, que ni siquiera ella misma es capaz de entender: "la indignación me invadía por completo, y en mi indignación se ocultaban muchas cosas, en su mayor parte formadas por sentimientos que no era capaz de comprender, sentimientos que quizá no llegue nunca a comprender" (91). Su desplazamiento no es lineal, ya que sus sentimientos no siguen un orden cronológico, sino que se movilizan entre emociones opuestas recurrentemente.

Para Kincaid, la muerte de su hermano no implica en ese preciso momento el reconocimiento del amor que ella sentía por él: "Cada vez que me venía a la memoria el hecho de que había muerto, era como si acabara de morir en aquel instante, y toda la experiencia por la que había pasado recomenzaba de nuevo. Mi hermano había muerto, y yo no le quería; o en cualquier caso, no le quería de la manera en que yo entiendo el amor" (123). Manifiesta el efecto de la muerte de su hermano en ella, manteniendo su postura de no sentir amor por él. De hecho, la autora señala la muerte de Devon como una interrupción en su vida: "reanudé la vida que su muerte había interrumpido" (125), y así regresa a su "vida ordenada" en Estados Unidos. Tiempo después, al ya haber retomado su vida cotidiana, Kincaid se encuentra con una mujer a la que había conocido en una reunión de un grupo de apoyo para los enfermos de sida en Antigua, y le cuenta que Devon había muerto, ella le responde estar al tanto, pues lo había conocido, ya que había hecho de su casa un lugar 
de reunión para que los homosexuales de Antigua pudieran reunirse en tranquilidad sin ser observados ni molestados por el resto de la sociedad, siendo Devon uno de esos homosexuales que concurría a ese lugar.

Al enterarse de la doble vida que vivía Devon, Kincaid comienza a entenderlo y a compartir con él la incapacidad de poder ser ella misma con las personas a las que mejor conoce (su familia), generando así un punto de contacto clave en su desplazamiento: "yo no podría haber llegado a ser escritora entre la gente a la que mejor conocía, no habría podido ser yo misma viviendo entre la gente a la que mejor conocía" (134). Es en este momento que ella se desplaza hasta el lugar de su hermano, el lugar de la incomprensión familiar que no le permite ser quien realmente es. Esta falta de comprensión, este temor y la necesidad de tener que alejarse, hace que se sienta más unida a él, como nunca sintió antes. La homosexualidad de Devon no es vista de una manera despectiva o punitiva por Kincaid, pues entiende sus conductas riesgosas como una máscara para protegerse de los prejuicios sociales. Kincaid empatiza con él, ya que ambos vivieron la incomprensión familiar: "estoy recordando la vida de mi hermano, estoy recordando mi propia vida" (138). Ahora Kincaid tiene una nueva imagen de su hermano: "Nunca olvidaré a mi hermano, pero no le recordaré por su sonrisa... nunca le olvidaré porque representa la vida que yo nunca tuve, una vida que, por razones que espero nunca estén del todo claras para mí, evité, o de la que escapé" (145-146). Kincaid puede ver en Devon la vida que ella hubiera tenido si se hubiera quedado en Antigua; siendo alguien que no es, escondiendo su propia esencia de los más cercanos. Kincaid se desplaza y cambia los juicios racionales por comprensión y piedad, se moviliza reemplazando la distancia por empatía entendiendo que lo que le ocurrió a Devon, le pudo haber ocurrido a ella misma.

Se puede ver entonces cómo el desplazamiento de ambas mujeres no invierte las posiciones, sino que "se destapa y se deshace la operación retórica responsable de la jerarquización y se produce un corrimiento significativo" (De Peretti 80), se desmontan las oposiciones dejando de ejercer un dominio unas sobre otras para operar en el mismo sistema sin oposiciones ni dominancia. 


\section{Reflexiones finales}

En ambas novelas se puede ver la temática de la enfermedad como eje central del desplazamiento de sus protagonistas. De diferentes maneras, una en primera persona y la otra como testigo, es la enfermedad la que corre el velo de la desinformación permitiendo a estas mujeres acceder a una realidad oculta que las moviliza. Si bien los desplazamientos experimentados por las protagonistas difieren en su forma, finalmente ambas mujeres logran alcanzar un punto de contacto con quienes en un comienzo fueron rechazados y/o juzgados por ellas. En el caso de $L a$ edad de hierro, la señora Curren experimenta un doble desplazamiento: la acerca a la comprensión de la realidad por la que atraviesa Sudáfrica durante el régimen del apartheid, así como hacia la figura de Vercueil -el vagabundo que representa la muerte- y que tiene precisamente como punto final el hecho de morir en sus brazos. En Mi hermano, Jamaica Kincaid se moviliza también hasta el lugar que ocupa su hermano Devon, llegando incluso a ser capaz de verse a sí misma en él. En ambos desplazamientos se puede ver cómo más que reemplazar las posiciones de dominancia las protagonistas se movilizan, desmontando las relaciones binarias y, de ese modo, anulando jerarquías y posiciones dominantes en estas relaciones. Cabe destacar, que el origen de estos desplazamientos es la enfermedad, un hecho violento, inesperado e involuntario, dado lo cual se podría pensar que si una situación de estas características no ocurriese las protagonistas no habrían experimentado dicho movimiento, convirtiéndose así estos desplazamientos en el efecto de una experiencia traumática más que en la voluntad de las protagonistas de movilizarse.

Ambos autores logran retratar la precaria situación social en que se desenvuelven las novelas, demostrando las diferencias que existen, en el caso de La edad de hierro, entre Ciudad del Cabo y un distrito segregado como Guguletu, plasmando al mismo tiempo lo diferente que es la vida para una mujer blanca (la señora Curren) y una de color (Florence) en el mismo país. Kincaid, por su parte, describe y compara la situación de Antigua y Estados Unidos, demostrando diferencias abismantes entre ambos países, desde el sistema de salud hasta las costumbres y educación de sus ciudadanos. Se puede ver entonces como la enfermedad traspasa a los sujetos enfermos proyectándose en los países que habitan, convirtiéndose en sociedades y países enfermos, que han caído en esta condición tras ser víctimas de invasiones externas, esta vez no por un 
virus, sino por la hegemonía colonizadora que llegó a invadir y destruir estas colonias.

\section{Bibliografía}

Barnett, Clive. "Constructions of Apartheid in the International Reception of the Novels of J.M. Coetzee". Journal of Southern African Studies 25 II (1999): 287-301.

Coetzee, J.M. La edad de hierro. [Ed. original1990]. Traducción Javier Calvo. Barcelona: Random House Mondadori, 2002.

De Peretti della Roca, Cristina. Jacques Derrida: Texto y deconstrucción. Barcelona: Editorial Anthropos, 1989.

Elias, Norbert. La soledad de los moribundos. Madrid: Fondo de Cultura Cconómica, 1987.

Foucault, Michel. Enfermedad mental y personalidad. Buenos Aires: Editorial Paidós, 1961.

Kincaid, Jamaica. Mi hermano. [Ed. original 1997]. Traducción Alejandro Pérez Viza. Santiago de Chile: LOM Ediciones, 2009. . "On Seeing England for the First Time". Transition 51 (1991): 3240.

Link, Daniel. "Enfermedad y cultura: política del monstruo". 249-265. Comp. Wolfgang Bongers y Tanja Olbrich. Literatura, cultura, enfermedad. Buenos Aires: Paidós, 2001.

Mezzadra, Sandro. “La condición postcolonial”. Comp. Sandro Mezzadra. Estudios postcoloniales. Ensayos fundamentales. España: Traficante de Sueños, 2008. 261-278.

Mignolo, Walter. "La razón postcolonial: Herencias coloniales y teorías postcoloniales". Revista chilena de literatura 47 (1995): 91-114

“Occidentalización, Imperialismo, Globalización: Herencias Coloniales y Teorías Postcoloniales. Revista Iberoamericana 61 (1995): 170-171. 
Pratt, Mary Louise. Ojos imperiales. Literatura de viajes y transculturación. México: Fondo de cultura económica, 2010.

Simmel, Georg. Cultura líquida y dinero. Fragmentos simmelianos de la modernidad. Barcelona: Anthropos, 2010.

Sontag, Susan. La enfermedad y sus metáforas y El SIDA y sus metáforas. Madrid: Taurus, 1996.

Spivak, Gayatri Chakravorti. Crítica de la razón poscolonial. Hacia una historia del presente evanescente. Madrid: Akal, 2010.

Stecher, Lucía. "Diáspora, duelo y memoria en Mi hermano de Jamaica Kincaid". Revista Chilena de Literatura 78 (2011): 185-203

Todorov, Tzvetan. Nosotros y los otros. Reflexión sobre la diversidad humana. México: Siglo XXI, 2011. 